\title{
Effects of coaches' timeouts on basketball teams' offensive and defensive performances according to momentary differences in score and game period
}

\author{
MIGUEL A. GÓMEZ ${ }^{1}$, SERGIO JIMÉNEZ ${ }^{2}$, RAFAEL NAVARRO ${ }^{3}$, CARLOS LAGO-PENAS $^{4}$, \\ \& JAIME SAMPAIO ${ }^{5}$
}

${ }^{1}$ Faculty of Physical Activity and Sport Sciences, Polytechnic University of Madrid, ${ }^{2}$ Faculty of Physical Education and Sport
Sciences, European University of Madrid, Madrid, Spain, ${ }^{3}$ Faculty of Physical Activity and Sport Sciences, University
Alfonso X El Sabio, Madrid, Spain, ${ }^{4}$ Faculty of Education and Sport, University of Vigo, Pontevedra, Spain, and ${ }^{5}$ Research
Center for Sport Sciences, Health and Human Development, University of Trás-os-Montes e Alto Douro, Vila Real, Portugal

\begin{abstract}
The aim of the present study was to assess the effects of game timeouts on basketball teams' offensive and defensive performances according to momentary differences in score and game period. The sample consisted of 144 timeouts registered during 18 basketball games randomly selected from the 2007 European Basketball Championship (Spain). For each timeout, five ball possessions were registered before $(n=493)$ and after the timeout $(n=475)$. The offensive and defensive efficiencies were registered across the first $35 \mathrm{~min}$ and last $5 \mathrm{~min}$ of games. A $k$-means cluster analysis classified the timeouts according to momentary score status as follows: losing ( -10 to -3 points), balanced ( -2 to 3 points), and winning (4 to 10 points). Repeated-measures analysis of variance identified statistically significant main effects between pre and post timeout offensive and defensive values. Chi-square analysis of game period identified a higher percentage of timeouts called during the last $5 \mathrm{~min}$ of a game compared with the first $35 \mathrm{~min}\left(64.9 \pm 9.1 \% \mathrm{vs} .35 .1 \pm 10.3 \% ; \chi^{2}=5.4\right.$, $P<0.05)$. Results showed higher post timeout offensive and defensive performances. No other effect or interaction was found for defensive performances. Offensive performances were better in the last $5 \mathrm{~min}$ of games, with the least differences when in balanced situations and greater differences when in winning situations. Results also showed one interaction between timeouts and momentary differences in score, with increased values when in losing and balanced situations but decreased values when in winning situations. Overall, the results suggest that coaches should examine offensive and defensive performances according to game period and differences in score when considering whether to call a timeout.
\end{abstract}

Keywords: Notational analysis, coaches, momentum, timeouts, basketball

\section{Introduction}

Team sports coaches take decisions during games that can have marked effects on performances and, ultimately, on the final outcome of games. Research has described the importance of coaches' cognitive processes when making decisions during competitive matches (Debanne \& Fontayne, 2009; Hastie, 1999; Jiménez \& Lorenzo, 2010; Zetou, Kourtesis, Giazitzi, \& Michalopoulou, 2008) and has also described the instructions given to the players (i.e. critical plays, the indications for starters or substitutes, last minutes of a game, timeout decisions) in different game situations (Allison \& Ayllon, 1980; Bar-Eli \& Tractinsky, 2000). During a game such as basketball, when players do not perform as the coach has planned and is expecting, he usually acts by instructing, substituting or calling a timeout. There are also additional reasons to call a timeout in basketball such as recovery from fatigue or interrupting the opponents' positive performance and consequent psychological advantage. This advantage has also been conceptualized as psychological momentum, as defined by an extra

Correspondence: M. A. Gómez, Faculty of Physical Activity and Sport Sciences, Polytechnic University of Madrid. C/ Martin Fierro 7. 28040 Madrid, Spain. E-mail: magor_2@yahoo.es 
psychological power that may change the interpersonal perceptions and then influences the players' mental and physical performances (Abenza, Alarcón, Ureña, \& Piñar, 2009; Burke, Aoyagi, Joyner, \& Burke, 2003; Burke, Burke, \& Joyner, 1999; Iso-Ahola \& Mobily, 1980; Mace, Lalli, Shea, \& Nevin, 1992; Roane, Kelley, Trosclair, \& Hauer, 2004; Smisson, Burke, Joyner, Munkasy, \& Blom, 2007). According to Burke et al. (2003, p. 11), momentum may be positive "when it is a psychological state of mind affecting performance in a positive direction where most everything seems to go right to the performer(s), for example, within a short period of time a player may steal the ball, score a 3-point fieldgoal and steal the ball again. However, momentum may be negative, when it is a psychological state of mind affecting performance in a negative direction where most everything seems to go wrong for the performer(s)". Burke et al. (1999, 2003) and Smisson et al. (2007) reported that positive momentum occurred most often due to the combination of a good performance by one team and a poor performance by the other.

Within basketball research, quantitative analysis of game-related statistics has been used to evaluate and discriminate team's and player's performances (Ibáñez et al., 2008; Ibáñez, García, Feu, Lorenzo, \& Sampaio, 2009; Sampaio, Drinkwater, \& Leite, 2010a; Sampaio, Lago, \& Drinkwater, 2010b). However, the use of these statistics to identify behavioural momentum and timeouts in particular is limited. Mace et al. (1992) found that calling a timeout from play is an effective intervention for reducing the opponent's rate of reinforcement, and thus its behavioural momentum. These authors also pointed out that the effectiveness of a team's performance relative to that of its opponent was sharply reduced following a timeout called by the opponent. More recently, Roane et al. (2004) found that a timeout called by the target team was effective in reducing the opponent's local rate of reinforcement.

Thus timeouts appear to be an adequate strategy to break the opponent's positive momentum. Duke and Corlett (1992) identified six factors that should be considered before calling a timeout: (1) offensive game events; (2) defensive game events; (3) the attentional state of the players; (4) the emotional state of the players; (5) the physical state of the players; and (6) strategy. Kozar and colleagues (Kozar, Whitfield, Lord, \& Mechikoff, 1993) examined the decisions of one coach when calling timeouts just before opposing players shoot free-throws during last $5 \mathrm{~min}$ of close games. They concluded that this strategy did not reduce free-throw percentage. Kozar et al., (1993) also stated that physiological benefits of timeouts near the end of a close game may allow fatigued players to recover enough and regain postural stability and motor control. According to these authors, the period of the game affects teams' performance and consequently increases the use of timeouts at critical times (Kozar et al., 1993; Mechikoff, Kozar, Lord, Whitfield, \& Brandenburg, 1990).

Finally, game score differences appear to be associated with coaches' strategy when calling timeouts (Kozar et al., 1993; Mace et al., 1992). Boutmans and Swillen (1991) examined the influence of timeouts on the final score of the team that made the call and found a positive relationship; also, the probability of a positive effect seemed to exist when the difference in points was no more than \pm 4 points.

Thus the aim of the present study was to examine the effect of timeouts in basketball offensive and defensive performances according to game period (first $35 \mathrm{~min}$ vs. last $5 \mathrm{~min}$ ) and momentary differences in points. We hypothesized that teams calling a timeout reduce their opponents' reinforcers and consequently points allowed and, simultaneously, increase their reinforcers after the timeout and consequently points scored. Also, there may be different consequences according to the game period and momentary differences in score.

\section{Methods}

Sample

The sample consisted of 144 timeouts registered from 18 basketball games randomly selected from the 2007 European Basketball Championship (Spain). The mean differences in score from all analysed games was $9.0 \pm 2.2$ points. Basketball rules (FIBA Rules, 2008, art. 18) allow coaches to call five timeouts during a game (two during the first half and three during the second half). Also, one TV-timeout is allowed in each period of a game in addition to the regular timeouts (art. E.2), which should be called within $5 \mathrm{~min}$ of the end of each period. Only timeouts called by coaches were analysed, and the data were collected from the official play-by-play boxscores of FIBA (International Basketball Federation). For each timeout, the five ball possessions before and after each timeout of the team that called it were registered where possible $(n=493$ and $n=475$ ball possessions, respectively).

\section{Variables}

Two- and 3-point field-goals scored and free-throws made were recorded for each ball possession to calculate team points scored and allowed. The variables were registered by highly experienced basketball analysts and over two games inter-rater reliability was very high (the lowest Cohen's kappa value was 0.99). 


\section{Dependent variables}

Teams' offensive and defensive performances were calculated as described by Oliver (2004), by dividing points scored (or allowed) by ball possessions. These ratings were calculated for the team that called a timeout, for the five ball possessions before and after each timeout.

\section{Independent variables}

A $k$-means cluster analysis was performed to identify a cut-off value of point differences and classify the timeouts (Sampaio et al., 2010a, 2010b). This algorithm aims to classify objects based on attributes into a $K$ number of groups (Bishop, 1995). The grouping is done by minimizing the sum of squares of distances between data and the corresponding cluster centroid, which represents the arithmetic mean for each dimension separately over all the points in the cluster. The results identified three clusters as follows: cluster 1 (losing, with a points differences of -10 to -3 points, $n=43$ ), cluster 2 (balanced, with a points differences of -2 to 3 points, $n=43$ ), and cluster 3 (winning, with a points differences of 4 to 10 points, $n=28$ ).

The available literature states that the last $5 \mathrm{~min}$ and any overtime may be considered as the critical moments of basketball games (Bar-Eli \& Tractinsky, 2000; Kaminsky, 1990; Kozar et al., 1993; Mechikoff et al., 1990; Navarro, Lorenzo, Gómez, \& Sampaio, 2009; Pereira, 2006). Therefore, based on this, game period was established as two categories: first $35 \mathrm{~min}$ of a game $(n=40)$ and last $5 \mathrm{~min}$ of a game $(n=74)$.

\section{Data analysis}

To allow inter-game comparisons, all data were converted to $z$-scores (Ibáñez et al., 2008). Descriptive results are presented as means and standard deviations. Repeated-measures analysis of variance (ANOVA) was performed for offensive and defensive performances according to game period and momentary differences in score. Where appropriate, Tukey's HSD test was used for multiple comparisons. Effect sizes (ES) were calculated and their interpretation was based on the following criteria: $<0.20=$ trivial, $0.20-0.59=$ small, $0.60-$ $1.19=$ moderate, $1.20-2.0=$ large, and $>2.0=$ very large (Hopkins, 2002). In addition, chi-square analysis was used to compare the frequency of timeouts called during the first $35 \mathrm{~min}$ of a game and during the last $5 \mathrm{~min}$ of a game. Statistical analyses were performed using STATISTICA release 8.0 (Statsoft, Tulsa, USA). Statistical significance was set at $P \leq 0.05$.

\section{Results}

Table I presents the descriptive results for offensive and defensive performances before and after timeouts according to period (first $35 \mathrm{~min}$ and last $5 \mathrm{~min}$ ) and momentary differences in score (losing, balanced or winning).

Chi-square results showed a higher percentage of timeouts called in the last 5 min compared with the first $35 \mathrm{~min}$ of games $\left(64.9 \%\right.$ vs. $35.1 \%$; $\chi^{2}=5.4$, $P<0.05$ ). Main effects and interactions (repeatedmeasures ANOVA) for offensive and defensive performances are presented in Table II. Results show better offensive and defensive performances

Table I. Descriptive results for the studied variables according to game period and differences in points before and after calling a timeout (results are the average from the five pre- and post-timeout ball possessions) (mean $\pm s$ )

\begin{tabular}{|c|c|c|c|c|c|c|}
\hline \multicolumn{4}{|c|}{ First $35 \min (n=40)$} & \multicolumn{2}{|c|}{ Last $5 \min (n=74)$} & \\
\hline Losing $(n=10)$ & $\begin{array}{c}\text { Balanced } \\
(n=16)\end{array}$ & $\begin{array}{l}\text { Winning } \\
(n=14)\end{array}$ & $\begin{array}{l}\text { Losing } \\
(n=33)\end{array}$ & $\begin{array}{c}\text { Balanced } \\
(n=27)\end{array}$ & $\begin{array}{l}\text { Winning } \\
(n=14)\end{array}$ & Total $(n=114)$ \\
\hline
\end{tabular}

$z$-scores

Offensive

\begin{tabular}{|c|c|c|c|c|c|c|c|}
\hline Pre & $-0.15 \pm 0.94$ & $-0.22 \pm 0.85$ & $-0.31 \pm 0.78$ & $0.19 \pm 0.83$ & $0.09 \pm 1.05$ & $0.85 \pm 1.25$ & $0.07 \pm 0.99$ \\
\hline Post & $-0.18 \pm 0.90$ & $0.20 \pm 0.95$ & $-0.49 \pm 1.21$ & $0.31 \pm 0.78$ & $0.39 \pm 1.27$ & $-0.11 \pm 0.74$ & $-0.08 \pm 0.93$ \\
\hline \multicolumn{8}{|c|}{ Defensive } \\
\hline Pre & $0.06 \pm 0.87$ & $-0.08 \pm 0.76$ & $-0.23 \pm 1.02$ & $-0.20 \pm 0.63$ & $0.39 \pm 1.76$ & $-0.04 \pm 0.77$ & $-0.19 \pm 0.81$ \\
\hline Post & $-0.12 \pm 0.94$ & $-0.13 \pm 1.03$ & $0.38 \pm 1.38$ & $-0.01 \pm 0.75$ & $0.06 \pm 1.05$ & $0.13 \pm 0.81$ & $-0.05 \pm 0.86$ \\
\hline \multicolumn{8}{|c|}{ Results } \\
\hline \multicolumn{8}{|c|}{ Dffensive } \\
\hline Pre & $45.5 \pm 47.4$ & $42.3 \pm 37.7$ & $37.8 \pm 34.6$ & $62.5 \pm 32.8$ & $51.5 \pm 46.5$ & $90.1 \pm 56.4$ & $51.47 \pm 45.11$ \\
\hline Post & $82.3 \pm 61.3$ & $84.1 \pm 65.3$ & $48.2 \pm 72.9$ & $117.9 \pm 36.7$ & $99.3 \pm 76.8$ & $71.2 \pm 49.6$ & $78.62 \pm 66.71$ \\
\hline \multicolumn{8}{|c|}{ Defensive } \\
\hline Pre & $116.2 \pm 67.0$ & $120.6 \pm 65.4$ & $96.6 \pm 76.2$ & $105.8 \pm 43.6$ & $166.6 \pm 141.8$ & $115.7 \pm 61.1$ & $119.25 \pm 79.1$ \\
\hline Post & $73.6 \pm 60.1$ & $77.3 \pm 65.6$ & $107.8 \pm 83.4$ & $77.1 \pm 54.3$ & $87.7 \pm 70.6$ & $90.2 \pm 52.6$ & $81.96 \pm 65.00$ \\
\hline
\end{tabular}


Table II. Results of repeated-measures ANOVA for the effects and interactions of pre- and post-timeout offensive and defensive performances according to momentary difference in score and game period

\begin{tabular}{|c|c|c|c|}
\hline Effects and Interactions & $F$ & $P$ & $\begin{array}{l}\text { Effect } \\
\text { size }\end{array}$ \\
\hline \multicolumn{4}{|l|}{ Offensive } \\
\hline Timeout & 10.60 & $0.001^{\star}$ & 0.10 \\
\hline $\begin{array}{l}\text { Timeout } \times \text { momentary difference } \\
\text { in score }\end{array}$ & 3.62 & $0.030^{\star}$ & 0.10 \\
\hline Timeout $\times$ game period & 0.19 & 0.665 & - \\
\hline $\begin{array}{l}\text { Timeout } \times \text { momentary difference } \\
\text { in score } \times \text { game period }\end{array}$ & 0.27 & 0.764 & - \\
\hline Momentary difference in score & 0.36 & 0.701 & - \\
\hline Period & 15.77 & $0.000^{\star}$ & 0.11 \\
\hline $\begin{array}{l}\text { Momentary difference in } \\
\text { score } \times \text { period }\end{array}$ & 4.21 & $0.018^{\star}$ & 0.07 \\
\hline \multicolumn{4}{|l|}{ Defensive } \\
\hline Timeout & 9.56 & $0.003^{\star}$ & 0.08 \\
\hline $\begin{array}{l}\text { Timeout } \times \text { momentary difference } \\
\text { in score }\end{array}$ & 1.68 & 0.192 & - \\
\hline Timeout $\times$ game period & 0.44 & 0.507 & - \\
\hline $\begin{array}{l}\text { Timeout } \times \text { momentary difference } \\
\text { in score } \times \text { game period }\end{array}$ & 0.98 & 0.379 & - \\
\hline Momentary difference in score & 1.30 & 0.278 & - \\
\hline Period & 0.67 & 0.417 & - \\
\hline $\begin{array}{l}\text { Momentary difference in } \\
\text { score } \times \text { period }\end{array}$ & 1.05 & 0.356 & - \\
\hline
\end{tabular}

${ }^{\star} P<0.05$.

after compared with before timeouts, although the effect size was considered trivial. No other effect or interaction was found for defensive performances. Offensive performances were better in the last $5 \mathrm{~min}$ of games, with the least differences when in balanced situations and greater differences when in winning situations (Figure 1). Results also showed one interaction between timeouts and momentary differences in score, with increased values when in losing and balanced situations but decreased values when in winning situations (Figure 2).

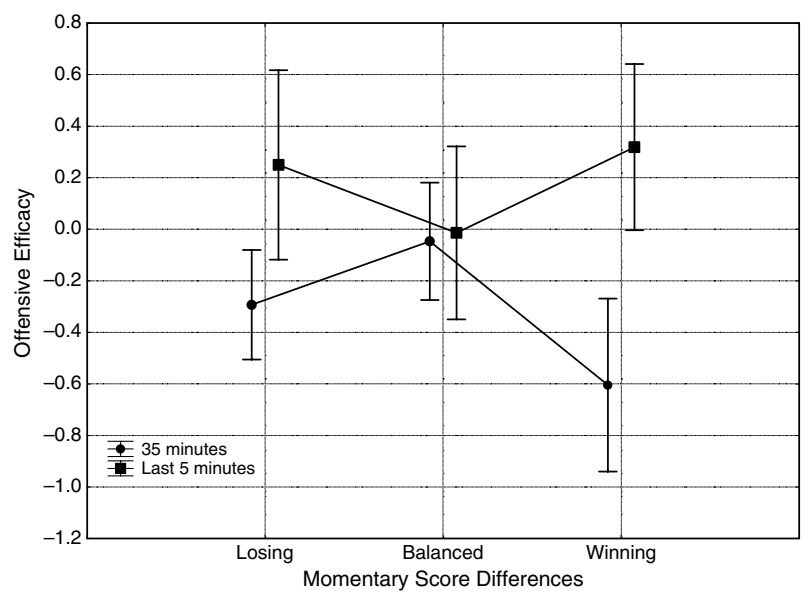

Figure 1. Offensive performances according to momentary differences in score and game period (results are presented as $z$-scores).

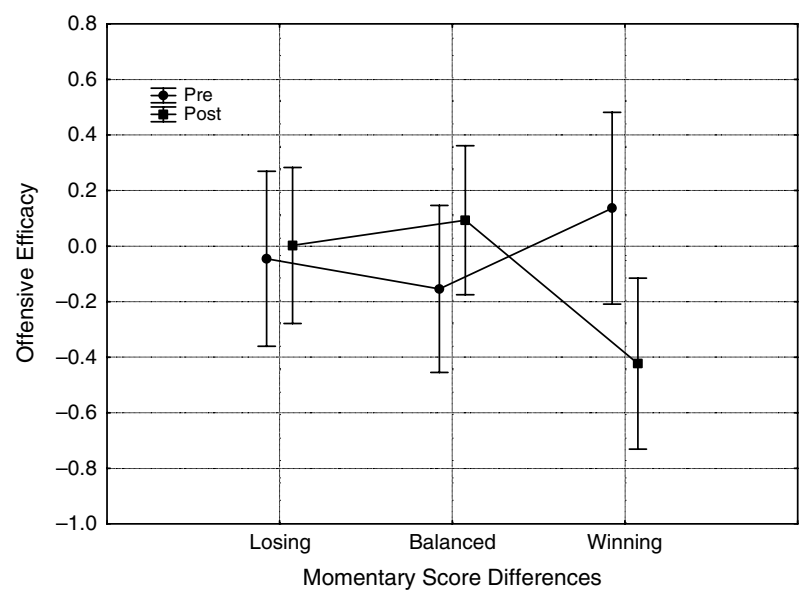

Figure 2. Offensive performances (pre and post timeout) according to differences in score (results are presented as $z$-scores).

\section{Discussion}

The aim of the present study was to examine the effect of timeouts on basketball offensive and defensive performances according to game period (first $35 \mathrm{~min}$ vs. last $5 \mathrm{~min}$ ) and momentary differences in score. We hypothesized that teams calling the timeouts would reduce their opponents' reinforcers and consequently the points allowed. Simultaneously, they would increase their reinforcement ratios after a timeout and consequently the points scored. Also, there may be different consequences according to the game period and momentary differences in score. It has been reported that the number of timeouts called increases during the last $5 \mathrm{~min}$ of a game (Kozar et al., 1993; Mechikoff et al., 1990). In the present study, $64.9 \%$ of timeouts were called during the last $5 \mathrm{~min}$ and $34.1 \%$ were called during the first $35 \mathrm{~min}$ of games. This result may be related to coaches' strategy late in the game. Indeed, it is usual for coaches to save two or three timeouts to be used during critical plays at the end of a game (Liccione, 2002).

Our results provide evidence that offensive and defensive performances were better after than before a timeout. As previously argued, timeouts were effective in decreasing the opponents' local rate of reinforcements and thus the points scored by opponents (Roane et al., 2004). As Mace et al. (1992) argued, calling a timeout early in an opponent's scoring streak may avoid the accumulation of "unanswered points". On the other hand, it is suggested that momentum occurs most frequently due to a combination of a good performance by one team and a poor performance by the other (Burke et al., 1999, 2003; Smisson et al., 2007). The present results provide some support for this argument, but also fail to isolate these effects. In fact, it is very difficult to 
credit if a team improved their offensive performance or their opponent's performance worsened.

One interesting finding from this study was that there were no statistically significant interactions in defensive efficiency coefficients. This fact may be related to the results of Duke and Corlett (1992), who found that coaches with the best players have higher expectations for an offensive performance, and the less talented teams often choose to concentrate on defence and on a non-offensive performance. Our study was focused on the timeouts called by the best 16 European national teams, and therefore it is possible that there was an increased emphasis on offensive rather than on defensive performances.

The identified interactions also provide new insights to understand the effects of timeouts on performance. The results of the present study do not include statistically significant differences for interactions between timeouts and game period. The only significant effect was for offensive performances according to game period and in interaction with momentary differences in score, with higher values during the last $5 \mathrm{~min}$ of games. This fact may improve coaches' knowledge about game dynamics, with a greater relevance of timeouts called during the last $5 \mathrm{~min}$ of a game. Ferreira and Barreto (2007) reported that a critical moment during a basketball game is any episode limited to $2-3 \mathrm{~min}$ or $4-8$ ball possessions with a points differential of 6 to 10 points. Indeed, our results indicate that timeouts during the last $5 \mathrm{~min}$ of games were called with a points differential of less than 10 points (analysing the preceding five ball possessions). Thus, a team's performance during these ball possessions is affected by critical situations that may improve or adversely affect the players' performance. These arguments may reflect the importance of effectiveness during the last $5 \mathrm{~min}$ of a game; for example, Navarro et al. (2009) identified 41 critical moments in basketball games and found that free-throws and 3-point fieldgoals discriminated between winning and losing teams. Thus, teams during this period of the game should select a better field-goal position or draw fouls that allow going to the free-throw line, and consequently try to be more effective in their ball possessions. Bar-Eli and Tractinsky (2000) highlighted that during critical moments of the game players may experience a "state of psychological crisis" that adversely affects their performance, and the coach will need to break the opponent's momentum and recover his players' performance during timeouts during these periods. Accordingly, timeouts are a resource used by coaches to provide a physical (Duke \& Corlett, 1992) and psychological (Kozar et al., 1993) benefit to players to recover enough motor control and mental stability that will allow them to generate better collective attacks and decision-making actions with higher efficiency during the last minutes of a game.

Available research reports that most timeouts are called with minor differences in score (Kozar et al., 1993). However, our results do not support this argument because a similar percentage of timeouts was called with losing and balanced scores. Despite this fact, some authors report that timeouts have a positive influence on the team that calls them when the difference in the score is no more than \pm 4 points (Boutmans \& Swillen, 1991). Based on our results, it was possible to identify an interaction between pre- and post-timeout offensive performances and momentary differences in score. This reflects the importance of coaches calling timeouts according to game dynamics when losing or winning. The results indicate that, when a timeout was called with a difference in score of between -2 and 3 points, the team that called it experienced an improved offensive performances, as suggested previously (Boutmans \& Swillen, 1991). When a team called a timeout when losing, the pre- and post-timeout results were similar. In contrast, when winning the results showed improved offensive performances after a timeout. These results might indicate that when the team has a balanced score, a timeout will help to facilitate a better offensive performance. However, when teams were winning, they did not improve their offensive performance after a timeout. It is possible that these situations reflect the moment at which, despite the team winning, their performance worsens and the coach decides to interrupt the game to reinvigorate the team with new instructions.

\section{Conclusions}

The current results suggest that coaches should examine offensive and defensive performances when considering whether to call a timeout. Also, the results point out the importance of offensive performances and their effects according to game period and momentary differences in score. It would be beneficial for coaches to base their timeout decisions according to these factors, trying to obtain better responses and consequently better performances after a timeout. Future research could use complementary approaches to investigate players' and coaches' perceptions about this topic and contrast them with the present results.

\section{References}

Abenza, L., Alarcón, F., Ureña, N., \& Piñar, M. I. (2009). Relation between the anxiety and performance of a basketball team during the competition. Revista de Psicología del Deporte, 18 (suppl.), 409-413. 
Allison, M. G., \& Ayllon, T. (1980). Behavioral coaching in the development of skills in football, gymnastics, and tennis. Fournal of Applied Behavior Analysis, 13, 297-314.

Bar-Eli, M., \& Tractinsky, N. (2000). Criticality of game situations and decision making in basketball: An application of performance crisis perspective. Psychology of Sport and Exercise, 1, 27-39.

Bishop, C. M. (1995). Neural networks for pattern recognition. Oxford: Oxford University Press.

Boutmans, J., \& Swillen, J. (1991). Time-out: Key to successful coaching. In G. Tenenbaum, \& D. Eiger (Eds.), Coach education: Proceedings of the Maccabiah-Wingate International Congress on Sport and Coaching (pp. 70-105). Netanya: Emmanuel Gill Publishing House.

Burke, K. L., Aoyagi, M. W., Joyner, B., \& Burke, M. M. (2003). Spectators' perceptions of positive momentum while attending NCAA men's and women's basketball regular season contests: Exploring the antecedents-consequences model. Athletic Insight, 5 (3), 10-18.

Burke, K. L., Burke, M. M., \& Joyner, B. (1999). Perceptions of momentum in college and high school basketball: An exploratory, case study investigation. Fournal of Sport Behavior, 22, 303-309.

Debanne, T., \& Fontayne, P. (2009). A study of successful experienced elite handball coaches' cognitive processes in competition situations. International fournal of Sports Science and Coaching, 4, 1-16.

Duke, A., \& Corlett, J. (1992). Factors affecting university women's basketball coaches' timeouts decisions. Canadian fournal of Sports Sciences, 17, 333-337.

Ferreira, A. P., \& Barreto, H. (2007). Critical moments in a basketball game: An approach from coaches' practical knowledge. Iberian Congress on Basketball Research, 4, 68-71.

Hastie, P. A. (1999). An instrument for recording coaches' comments and instructions during time-outs. Fournal of Sport Behavior, 22, 467-478.

Hopkins, W. (2002). A new view of statistics (retrieved 26 April 2008 from: http://www.sportsci.org/resource/stats/effectmag. html).

Ibáñez, S. J., García, J., Feu, S., Lorenzo, A., \& Sampaio, J. (2009). Effects of consecutive basketball games on the gamerelated statistics that discriminate winning and losing teams. Fournal of Sports Science and Medicine, 8, 458-462.

Ibáñez, S. J., Sampaio, J., Feu, S., Lorenzo, A., Gómez, M. A., \& Ortega, E. (2008). Basketball game-related statistics that discriminate between teams' season-long success. European Fournal of Sport Science, 8, 369-372.

Iso-Ahola, S. E., \& Mobily, K. (1980). Psychological momentum: A phenomenon and an empirical (unobtrusive) validation of its influence in a competitive sport tournament. Psychological Reports, 46, 391-401.

Jiménez, S., \& Lorenzo, A. (2010). El buen entrenador como experto adaptativo que lidera el grupo. Revista de Psicología del Deporte, 19 (1), 9-21.

Kaminsky, J. (1990). Critical game periods in relation to team success in college basketball. Unpublished Master's Thesis, Kent State University, Kent, $\mathrm{OH}$.

Kozar, B., Whitfield, K. E., Lord, R. H., \& Mechikoff, R. A. (1993). Timeouts before free-throws: Do the statistics support the strategy? Perceptual and Motor Skills, 76, 47-50.

Liccione, D. (2002). Take the time to win! Coach and Athletic Director, 72, 24-27.

Mace, F. C., Lalli, J. S., Shea, M. C., \& Nevin, J. A. (1992). Behavioral momentum in college basketball. Fournal of Applied Behavior Analysis, 25, 657-663.

Mechikoff, R. A., Kozar, B., Lord, R. H., Whitfield, K. E., \& Brandenburg, J. (1990). Perceptions of basketball coaches. The Basketball Bulletin, Fall, pp. 72-75.

Navarro, R. M., Lorenzo, A., Gómez, M. A., \& Sampaio, J. (2009). Analysis of critical moments in the League ACB 2007-2008. Revista de Psicología del Deporte, 18 (suppl.), 391-395.

Oliver, D. (2004). Basketball on paper: Rules and tools for performance analysis. Washington, DC: Brassey's, Inc.

Pereira, A. P. (2006). Criticality and critical moments: Applications in the basketball game. Unpublished Master's Thesis, Faculty of Human Movement. Universidade Técnica de Lisboa, Lisbon, Portugal.

Roane, H. S., Kelley, M. E., Trosclair, N. M., \& Hauer, L. S. (2004). Behavioral momentum in sports: A partial replication with women's basketball. Fournal of Applied Behavior Analysis, 37, 385-390.

Sampaio, J., Drinkwater, E. J., \& Leite, N. (2010a). Effects of season period, team quality, and playing time on basketball players' game-related statistics. European fournal of Sport Science, 10, 141-149.

Sampaio, J., Lago, C., \& Drinkwater, E. J. (2010b). Explanations for the United States of America's dominance in basketball at the Beijing Olympic Games (2008). Fournal of Sports Sciences, $28,147-152$.

Smisson, C. P., Burke, K. L., Joyner, B., Munkasy, B. A., \& Blom, L. C. (2007). Spectators' perceptions of momentum and personal control: Testing the antecedents-consequences model. Athletic Insight, 9 (1), 79-90.

Zetou, E., Kourtesis, T., Giazitzi, K., \& Michalopoulou, M. (2008). Management and content analysis of timeouts during volleyball games. International fournal of Performance Analysis in Sport, 8, 44-55. 